\title{
A case of ovarian torsion: To pex or not to pex?
}

Elroy Weledji ${ }^{1}$ and Adolphe Elong ${ }^{1}$

${ }^{1}$ University of Buea

April 25, 2021

\begin{abstract}
Torsion of the ovary is a common gynaecological surgery emergency. It is important to distinguish torsion of ovary from torsion of ovarian cyst as their sequelae and management are different as seen in the lower salvage rate of the former. A history of previous episodes may suggest spontaneously resolving torsion.
\end{abstract}

\section{Hosted file}

ovarian torsion -to pex or not to pex (clinical case report).pdf available at https:// authorea.com/users/352246/articles/519448-a-case-of-ovarian-torsion-to-pex-or-not-to-pex 